\title{
Sensitivity of simulated surface runoff to mesoscale meteorological model resolution in a linked-model experiment
}

\author{
M. N . Lakhtakia*, Z. Yu, B. Yarnal, R. A. White, D. A. Miller \\ Earth System Science Center and EMS Environment Institute, The Pennsylvania State University, 248 Deike Building, \\ University Park, Pennsylvania 16802, USA
}

\begin{abstract}
A mesoscale meteorological model (MM5) is linked to a hydrologic model to simulate river-basin response to single-storm events. M M 5 uses a nested-domain configuration, with grid increments of 36, 12 and $4 \mathrm{~km}$, to produce high-resolution precipitation fields for input to the hydrologic model. A problem that will arise when performing longer-term simulations is the extraordinary computational demands of the nested MM5. To evaluate the effect that the MM 5 resolution has on the simulation of direct surface runoff in the linked-model experiments, and with the goal of decreasing the computational intensity of these experiments, 3 single-storm events and their basin response were simulated with MM 5 using 3 domain set-ups: 36-12-4, 36-12, and $36 \mathrm{~km}$. The results show that the 36-12 km set-up generates similar patterns of precipitation and direct surface runoff to those of the 36-12-4 km domain set-up. The $36 \mathrm{~km}$ domain set-up produces unrepresentative precipitation distributions in time and space. It is concluded that $12 \mathrm{~km}$ precipitation fields may be a suitable compromise, providing sufficient resolution for simulating the basin response to climate variation and change.
\end{abstract}

KEY WORDS: Mesoscale meteorological model · Hydrologic model · Hydroclimatic modeling . River-basin hydrology · Susquehanna River Basin · SRBEX

\section{INTRODUCTION}

The need to understand the regional impacts of climate change has produced a research focus on climate simulations at high spatial and temporal resolutions (Kattenberg et al. 1996, Crane et al. 1999). Regional change scenarios are being produced by relatively high-resolution general circulation models (GCMs), nested regional climate models (RegCMs, also known as Limited Area Models), and statistical downscaling. The current generation of high-resolution GCMs use grid increments of approximately $1^{\circ}$ latitude $\times 1^{\circ}$ longitude. Detailed climate simulations require finer resolution than this (Beniston et al. 1997), and this is provided by RegCMs embedded in GCMs with lower resolution (e.g. Giorgi \& M earns 1991). Interactions between the 2 models are 1-directional at present (i.e. the GCM is

*E-mail: lakht@essc.psu.edu integrated forward in time, and the output is used to constrain the evolution of the RegCM). Statistical downscaling is an alternative to numerical solutions. It derives transfer functions linking the larger-scale features of GCM s (such as the atmospheric circulation) to local climate. A variety of statistical procedures have been developed (e.g. Hewitson \& Crane 1996).

The Susquehanna River Basin Experiment (SRBEX), an Interdisciplinary Science (IDS) team project funded by NASA EOS, took 3 approaches to generate detailed climate scenarios of precipitation for use in regional climate impact analysis. The first approach was to nest RegCM 2 (Giorgi et al. 1993a,b) in the GENESIS GCM (Thompson \& Pollard 1995). Using this approach, J enkins \& Barron (1997) found that the Susquehanna River Basin (SRB) experiences an approximately $20 \%$ increase in precipitation with a doubling of $\mathrm{CO}_{2}$, with most precipitation falling in winter. The second approach was to use artificial neural networks to downscale the relationship between atmospheric circulation 
and surface climate. For example, using the second version of GENESIS, Crane \& Hewitson (1998) determined that doubled $\mathrm{CO}_{2}$ conditions result in an increase in annual precipitation of more than $30 \%$ in the $\mathrm{SRB}$, with the majority of that increase taking place during summer. A third group of SRBEX IDS investigators took a slightly different path to generating highresolution weather and climate scenarios.

The third group described above used the Penn State/NCAR mesoscale meteorological model version 5 (M M 5), with a nested-domain configuration, to simulate high-resolution precipitation fields over the SRB. Precipitation is the variable linking MM 5 to a surface and ground-water hydrologic model (Lakhtakia et al. 1998) or to the Hydrologic M odel System (HMS; Yu et al. 1999a). For these applications, MM 5 was set up with a parent domain (Domain 1, with a $36 \mathrm{~km}$ grid increment) and 2 nested, telescoping domains over the SRB (Domain 2, with a $12 \mathrm{~km}$ grid increment, and Domain 3, with a $4 \mathrm{~km}$ grid increment) (Fig. 1). The M M 5-simulated $4 \mathrm{~km}$ precipitation fields were used to drive the hydrologic models for 3 single-storm events over the Upper West Branch of the SRB. These applications have resulted in acceptable simulations of the river-basin response ( $\mathrm{Yu}$ et al. 1999a). The long-term goal of this research is to evolve MM5 into a highresolution RegCM that can furnish scenarios at a variety of time scales, and that will drive process-based basin-scale hydrologic models.

One practical problem that arose during the abovementioned applications is the computational intensity

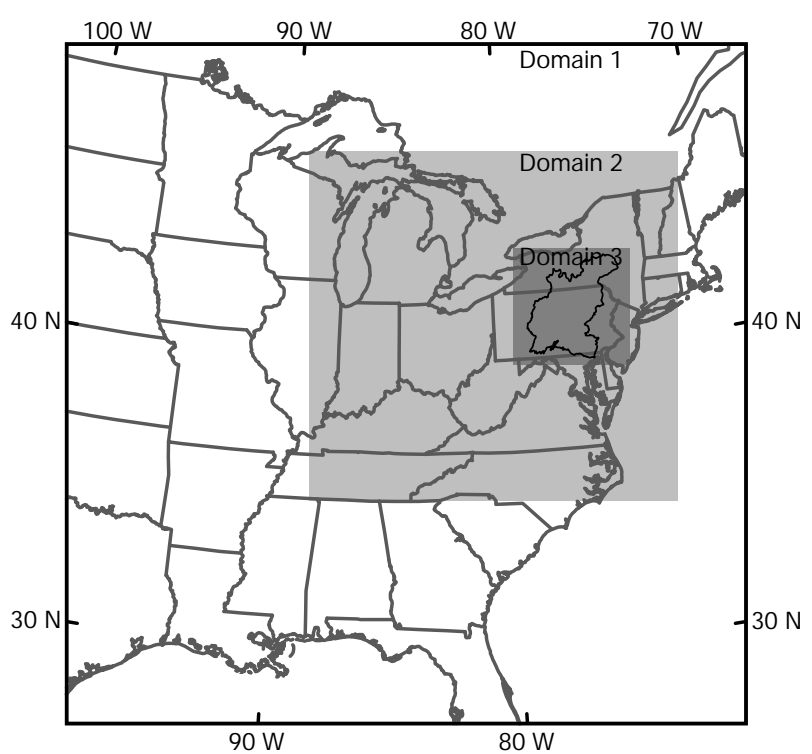

Fig. 1. The 3 nested domains used in the Penn State/NCAR mesoscale meteorological model version 5 (MM5), showing the outline of the Susquehanna River Basin (SRB) within Domain 3 of the nested MM 5 runs. This led the investigators to question the need for the 36-12-4 km domain nesting. Does HMS require $4 \mathrm{~km}$ inputs? Do the 12 or $36 \mathrm{~km}$ domains provide enough spatial detail to simulate the basin hydrology of the SRB accurately? Answering such simple questions is important to the entire enterprise of high-resolution regional climate modeling because it provides empirical guidelines for how far to advance model development. In other words, how fine must the grid increment of regional climate scenarios be for applications?

The purpose of this paper is to answer the above questions by applying MM 5 with 3 different nesteddomain set-ups to 3 single-storm events over the SRB. The resulting simulated precipitation data sets are used as inputs to a rainfall-runoff version of HMS to evaluate the effect that the M M 5 resolution has on the simulated direct surface runoff. For the purpose of this work, the linked-model results from the $36-12-4 \mathrm{~km}$ M M 5-domain set-up are considered the best the models can perform at the present time, and, as such, they are called the control runs. The results from the 36-12 and $36 \mathrm{~km} \mathrm{M} \mathrm{M} \mathrm{5-domain} \mathrm{set-ups} \mathrm{are} \mathrm{compared} \mathrm{to} \mathrm{the}$ results from the control runs. The basin selected for this experiment is the Upper West Branch of the SRB, located in north-central Pennsylvania, upstream from Williamsport (Fig. 2). The following sections contain a description of MM5 and HMS, a description of the study area and season, a discussion of the results and related issues, and the conclusions.

\section{THE MESOSCALE METEOROLOGICAL MODEL}

MM5 is a 3-dimensional, primitive-equation mesoscale meteorological model, capable of simulating and predicting a large variety of atmospheric phenomena, and producing high-resolution, 4-dimensional (3 dimensions in space and 1 dimension in time), dynamically consistent data sets (Dudhia 1993, Grell et al. 1995). For the particular applications described here, M M 5 was used in the non-hydrostatic mode, with the multi-level Blackadar-type planetary boundary layer parameterization (Zhang \& Anthes 1982) and Grell cumulus parameterization (Grell 1993). The cumulus parameterization scheme was used for Domains 1 and 2 , but not for Domain 3, because most of the precipitation processes are resolved with a $4 \mathrm{~km}$ grid increment.

This experiment uses 3 nested horizontal domains (Fig. 1). Domain 1 is centered at $39.0^{\circ} \mathrm{N}, 84.5^{\circ} \mathrm{W}$, and covers the eastern half of the United States with a mesh that contains 71 grid points in both the northsouth and west-east directions, and a grid increment of $36 \mathrm{~km}$. Domain 2 is nested within Domain 1 , has a mesh with 109 grid points in the north-south direction 


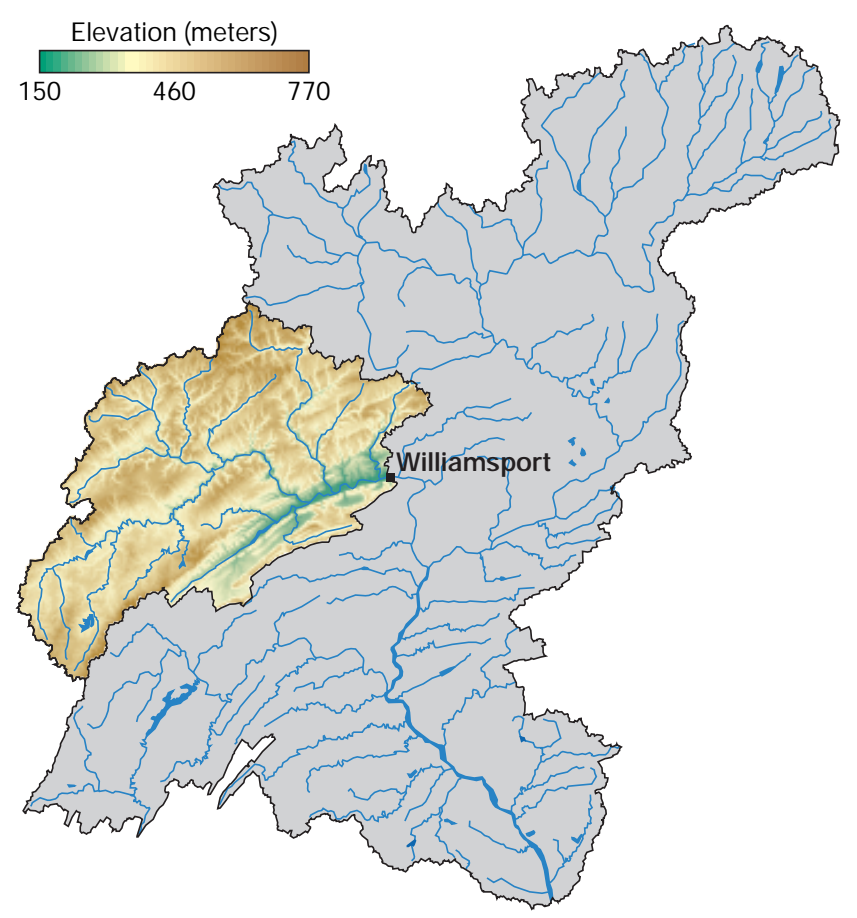

Fig. 2. SRB channel network, showing the $1 \mathrm{~km}$ topography of the Upper West Branch of the SRB and the location of Williamsport, Pennsylvania

and 115 grid points in the west-east direction, and a $12 \mathrm{~km}$ grid increment. Domain 2 is shifted north and east away from the center of Domain 1 . Domain 3 is nested within Domain 2, has a $4 \mathrm{~km}$ grid increment, and covers an area slightly larger than, and encompassing, the SRB (Fig. 1), with a mesh that contains 109 grid points in both directions. All 3 domains have 20 vertical levels, which are unequally distributed from the surface to $100 \mathrm{mb}$, with higher resolution near the surface. The grid-increment ratio from a larger domain (e.g. Domain 1) to the next nested domain (e.g. Domain 2) is 1:3 and is fixed in MM5; as a result, the time-step ratio is also 1:3. This results in a significant computational-time increase when adding a nested domain.

Three domain set-ups are used. The telescoped nesting of Domains 1, 2, and 3 (as shown in Fig. 1) is referred to as the 3 -domain case (3DC). The 2 other domain set-ups are the 2-domain case (2DC), which nests Domain 2 in Domain 1, and the 1-domain case (1DC) with the $36 \mathrm{~km}$ domain only. These 3 MM 5 domain configurations (i.e. 1DC, 2DC, and 3DC) are used to simulate 3 single-storm events passing over the SRB. In each case, the simulated precipitation data on the highest-resolution domain is used to drive HMS; that is, Domain 3 precipitation is used in 3DC, Domain 2 precipitation is used in 2DC, and Domain 1 precipita- tion is used in 1DC. The 3DC results applied to the first storm and to all 3 storms are discussed in Lakhtakia et al. (1998) and Yu et al. (1999a), respectively. The 3DC results are considered the control experiments here.

Both nested cases (2DC and 3DC) use a 2-way interactive nesting procedure. Using the 2DC as an example, this nesting procedure works as follows: (1) Domain 1 (the parent domain) is integrated 1 time step; (2) the parent domain provides the lateral boundary conditions of the meteorological fields to Domain 2 (the child domain); (3) the child domain is integrated 3 time steps (as a result of the 1:3 time-step ratio); (4) the child domain feeds back the meteorological fields to the parent domain, and the cycle ends, going back to Step 1. This procedure keeps the nested-domain solutions from diverging (Grell et al. 1995). However, the 2-way interactive nesting procedure is more computerspace and time intensive than the simpler 1-way nesting procedure. In the 1-way nesting procedure, the simulation for the parent domain is performed first, followed by the simulation for the child domain, using the output from the parent domain as lateral boundary conditions, but without the possibility of feedback from the child domain to the parent domain.

Four data sets were used to define the initial and temporal lateral boundary conditions for MM5. The first data set is the National Meteorological Center's (NMC) global tropospheric analyses, which have a $2.5^{\circ}$ latitude-longitude resolution. This data set was used for Storm 1. Some of the data in the NM C data set were missing during the period of the simulation of Storms 2 and 3. Therefore, the European Center for MediumRange Weather Forecast (ECMWF) global tropospheric analyses data set, which has similar characteristics to the NMC data set, was used for Storms 2 and 3. The other 2 data sets contain the NMC upper-air and surface observations, and were used for all 3 storms.

To create the initial and boundary conditions for the model simulations, the M M 5 pre-processing programs first interpolate the low-resolution global analyses to the M M 5 domains. In a second step, the interpolated analyses are enhanced by objectively analyzing the observed upper-air and surface data ( $M$ anning \& Haagenson 1992). The result is a 3-dimensional analysis of the meteorological variables that contains some mesoscale information. In a final step, the 3-dimensional analyzed data set is interpolated vertically to the vertical coordinates of M M 5. This multi-step process is performed for Domain 1 in the 1DC, and for Domains 1 and 2 in the 2DC and 3DC. In all 3 cases, Domain 1 is expanded by 8 horizontal grid points on each side so that the analyses close to the lateral boundaries are of the same quality as in the interior of the domain.

This process produces the initial conditions and the temporally variable lateral boundary conditions for 
Domain 1 in the $1 D C$. In the 2DC and 3DC, this process produces the initial conditions for Domains 1 and 2, and the temporally variable lateral boundary conditions for Domain 1. To create the initial conditions for Domain 3 in the 3DC, M M 5 spatially interpolates the initial conditions for Domain 2 at the initial time of the simulation. This procedure is used because the $4 \mathrm{~km}$ grid increment for Domain 3 is too small compared to the distance between the observation stations. Therefore, no additional mesoscale information would be gained by performing the objective analysis (as described in the previous paragraph), as opposed to a simpler horizontal interpolation. As explained previously, the boundary conditions for Domain 2 (2DC and $3 D C$ ), and for Domain 3 (3DC) are given during the M M 5 integration by Domains 1 and 2, respectively.

\section{THE HYDROLOGIC MODEL}

The correct prediction of surface runoff and subsurface infiltration is crucial for simulating streamflow. The rainfall-runoff scheme separates precipitation into components of surface runoff and subsurface infiltration at each time step during a storm event. The rainfall-runoff scheme used in this study is a part of a Geographic Information System (GIS)-based Hydrologic Model System (GIS HMS) developed by Yu et al. (1999b). GIS HMS is similar to the Curve Number approach of Soil Conservation Survey (USDA-SCS 1972). A curve number is derived for each grid cell based on soil and vegetation information, and it is used, together with the rainfall intensity, in the calculation of surface runoff and subsurface infiltration at each time step.

The GIS HMS uses ARC Macro Language (AML) in the ARC/INFO GIS, which offers many raster functions that are useful for hydrologic applications. The spatial approach in GIS HMS combines GIS data organization and distributed hydrologic modeling. The model architecture and design consistently consider data and processes at various scales (e.g. local, catchment, watershed, and regional). GIS HMS includes thematic maps (topography, soil, and vegetation) and spatial and temporal hydrologic data (precipitation and surface runoff).

The data analysis and the hydrologic simulation procedures used ARC/INFO GIS software. The exceptions were the computation of the curve number grid and the production of the precipitation grids from the M M 5-simulated precipitation, which were performed using the Land Analysis System (LAS). The hydrologic simulation was performed using a $1 \mathrm{~km}$ grid-cell increment; thus, the input data sets had to be resampled to this increment before being fed to the model. Digital Elevation Models (DEMs) at 3 arc second spacing (approximately $72 \times 90 \mathrm{~m}$ grid) for the Upper West Branch of the SRB were obtained from the United States Geological Survey (USGS). The resampled DEM (Fig. 2) was used to delineate the basin boundaries and stream networks in ARC/INFO. The delineated basin boundaries were converted to polygon format for clipping other coverages (i.e. soil, vegetation, stream networks, curve number, and precipitation) needed for the GIS HMS simulation.

A curve number was derived for each grid cell in the GIS HMS domain by combining hydrologic soil group data extracted by Miller \& White (1998) from the State Soil Geographic (STATSGO) data set (compiled by the Natural Resources Conservation Service, United States Department of Agriculture) with land-cover data derived from Landsat Thematic M apper satellite imagery (as part of the Environmental Mapping and Assessment Program [EMAP] of the United States Environmental Protection Agency) (USEPA 1994). Gridded hourly precipitation data were interpolated from the MM5-simulated precipitation. For each storm event, the hydrologic response was simulated for the entire drainage area, with the total amount of water accumulated at the basin outlet.

Channel routing is available in the GIS HMS to account for the lagged streamflow response due to the channel delay (Bedient \& Huber 1992). In GIS HMS, the channel-routing scheme treats the computed surface runoff hydrograph as the inflow and the routed runoff hydrograph is produced as the outflow at the basin outlet. The surface runoff for each time step at the basin outlet is the accumulated amount of water for the entire drainage area. However, the precipitation pulses are difficult to distinguish on the simulated runoff hydrograph because these pulses are smoothed out by the application of the channel-routing algorithm (Yu et al. 1999a). As the focus of this work is to study the effect of the M M 5 grid increment on the simulated hydrologic response, the channel-routing scheme was not used. In this way, the spatial and temporal differences in the simulated surface runoffs that were generated by the various MM5-simulated precipitation patterns could be evaluated more easily.

The physical setting and the HMS data preparation (e.g. physical and hydrologic parameters) are described in detail in previous papers (Lakhtakia et al. 1998, Yu et al. 1999b).

\section{STUDY AREA AND SEASON}

The study basin selected for these experiments is the Upper West Branch of the SRB, whose outlet is located near Williamsport, Pennsylvania (Fig. 2). This basin was chosen because it is relatively large $\left(14710 \mathrm{~km}^{2}\right)$, 
while streamflow data from gauges are readily available and it is supported by good digital climate, topographic, and soil data. The basin's headwaters rise in the Appalachian Plateau, a rugged, dissected and forested region, with thin, infertile, and rocky soils underlain by mildly warped sedimentary rocks. Downstream, the folded sandstone, limestone and shale layers of the Appalachian M ountains create a series of parallel sandstone ridges (forested) with shale and limestone valleys (farmed) that sweep southwest to northeast through the study area ( $M$ arsh \& Lewis 1995).

The choice of April and May storms simplifies the numerical models' initial conditions. Snowcover is gone by mid-April and the soil-water content of the Upper West Branch of the SRB tends to be moderate to high at this time of the year.

\section{RESULTS}

Three storm systems were simulated that occurred in April 1986 (Storm 1), May 1984 (Storm 2), and M ay 1988 (Storm 3). The M M 5 and GIS HMS time domains for each of these storms are given in Table 1 . The following sections include a brief description of each storm and the results from M M 5 and GIS HMS, focusing on the differences between 3DC and the other 2 cases (1DC and 2DC) for each storm.

The storm descriptions are based on daily weather maps from the National Oceanic and Atmospheric Administration (NOAA 1984, 1986, 1988), hourly precipitation totals from the National Weather Service first-order weather station at Williamsport, and hourly analyzed precipitation fields from the National M eteorological Center. Lakhtakia et al. (1998) gave a more complete characterization of Storm 1, and $\mathrm{Yu}$ et al. (1999a) described all 3 storms in greater detail than presented here.

\subsection{Storm 1: A pril 1986}

Storm 1 was a simple wave cyclone that migrated west to east across the United States during 11 to 17 A pril 1986. The Upper West Branch of the SRB was directly in the path of this zonally migrating low. As a result, this area experienced first the cool sector north of the warm front, then the slow passage of the system's occluded sector. This positioning provided the basin with thick stratiform clouds and particularly prolonged rainfall that started in the morning of $15 \mathrm{April}$ and concluded late in the evening of 17 A pril. Rainfall
Table 1. Time domains of the 3 storms used in the linked simulations. UTC: Universal Time Coordinate

\begin{tabular}{|lcc|}
\hline \multirow{2}{*}{ Storm } & M M5 simulation & GIS HMS simulation \\
\hline 1 & 12:00 UTC 14 Apr- & 12:00 UTC 14 Apr- \\
& 12:00 UTC 18 Apr 1986 & 20:00 UTC 22 Apr 1986 \\
2 & 12:00 UTC 27 May- & 12:00 UTC 27 May- \\
& 00:00 UTC 30 May 1984 & 20:00 UTC 4 J un 1984 \\
3 & 12:00 UTC 17 May- & 12:00 UTC 17 May- \\
& 12:00 UTC 21 May 1988 & 20:00 UTC 25 May 1988 \\
\end{tabular}

rates over the Upper West Branch of the SRB were low, averaging approximately $2 \mathrm{~mm} \mathrm{~h}^{-1}$. No hourly readings exceeded $7 \mathrm{~mm} \mathrm{~h}^{-1}$.

The temporal evolution of the areally averaged M M 5-simulated precipitation and the GIS-HMS-simulated direct surface runoff for Storm 1 are shown in Fig. 3 for the 1DC, 2DC and 3DC. The precipitation
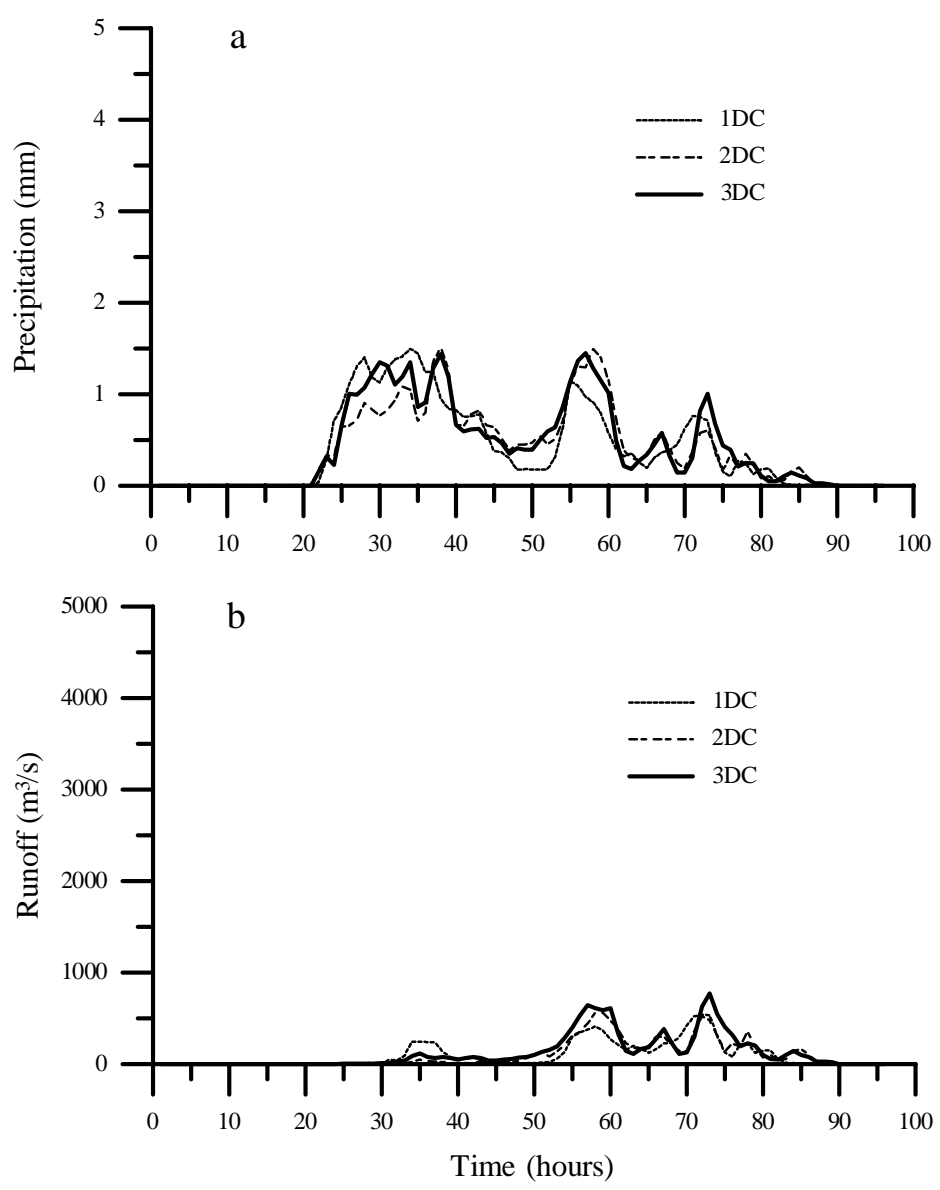

Fig. 3. Temporal evolution of the areally averaged (a) MM5-simulated precipitation and (b) GIS-HMS-simulated direct surface runoff over the Upper West Branch of the SRB for the 1DC, 2DC and 3DC for Storm 1 (starting at 12:00 UTC 14 A pril 1986) 


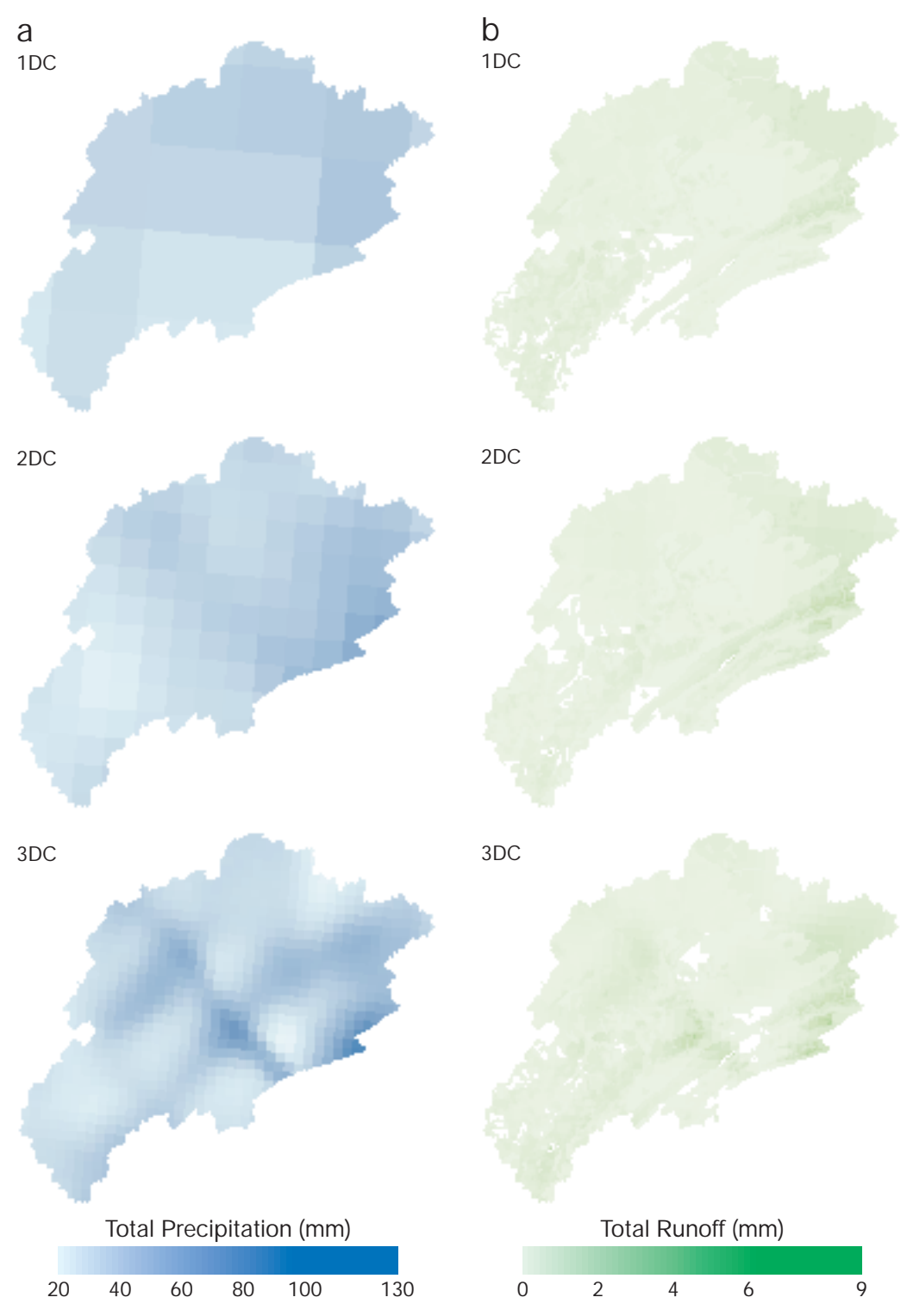

Fig. 4. Spatial distribution of the temporally integrated (a) MM5-simulated precipitation and (b) GIS-HMS-simulated direct surface runoff over the Upper West Branch of the SRB for the 1DC, 2DC and 3DC for Storm 1 (starting at 12:00 UTC 14 A pril 1986)

traces compare well among the 3 M M 5 domain configurations (Fig. 3a). All 3 cases show the low intensity, steady precipitation characteristic of this particular storm. However, the 2DC trace follows the 3DC trace more consistently than the 1DC trace does. This may be a result of the MM5 initialization procedure, in which the initial conditions for Domain 3 in 3DC are interpolated from the initial conditions for Domain 2, instead of resulting from the objective analysis of the observations as for Domains 1 and 2. However, the responses of the GIS-HM S-simulated surface runoff to the precipitation produced by the 3 cases are some- what different (Fig. 3b). In general, the simulation with the 3DC precipitation has the highest surface runoff hydrograph peaks, while the 2DC precipitation produces a hydrograph that is relatively close to the 3DC, compared to the 1DC.

The spatial distribution of the temporally integrated precipitation and surface runoff for Storm 1 for the 3 cases are shown in Fig. 4. In all 3 cases, a precipitation maximum is located along the eastern edge of the basin near the basin outlet, while a precipitation minimum appears along the southern boundary of the basin (IDC) or the southwestern boundary of the basin (1DC, 2DC and 3DC). A secondary maximum that appears in the geographical center of the basin in the $3 D C$ is hinted at in the $2 D C$, but does not exist in the 1DC. As expected, the spatial variability of the precipitation increases with the grid resolution. The patterns of precipitation for the 3DC and 2DC are somewhat similar, while the IDC only agrees in the location of the primary maximum and the southwestern minimum. The maximum (minimum) value of precipitation for Storm 1 increases (decreases) with the grid resolution (Table 2). The mean value increases with the grid resolution, but the difference between the IDC and 3DC is small.

Fig. $4 \mathrm{~b}$ shows that the general patterns of the spatial distribution of the temporally integrated surface runoff are similar for all 3 cases. These results indicate that the spatial distribution of surface runoff is affected not only by precipitation, but also by soil properties and vegetation types. The mean and maximum values of total surface runoff for Storm 1 increase with the grid resolution (Table 2).

\subsection{Storm 2: May 1984}

Storm 2 was also a migratory wave cyclone, crossing the country from $25 \mathrm{M}$ ay to $1 \mathrm{~J}$ une 1984 . Unlike the A pril 1986 storm, the May 1984 system had a more meridional, southwest-to-northeast trajectory and was more complex, possessing 2 surface low-pressure centers. The secondary surface low was the first to arrive, 
Table 2. Maximum, minimum, and mean values of the total MM5-simulated precipitation $(\mathrm{mm})$ and GIS-HMS-simulated runoff $(\mathrm{mm})$ for the 1DC, 2DC and 3DC and for the 3 storms

\begin{tabular}{|llrrrrrr|}
\hline & & \multicolumn{2}{c}{ Storm 1 } & \multicolumn{2}{c}{ Storm 2 } & \multicolumn{2}{c|}{ Storm 3 } \\
& & Rainfall & Runoff & Rainfall & Runoff & Rainfall & Runoff \\
\hline 1DC & Minimum & 28.6 & 0.00 & 25.2 & 0.00 & 22.1 & 0.00 \\
& Maximum & 48.3 & 1.85 & 78.3 & 5.79 & 59.2 & 2.91 \\
& M ean & 39.1 & 0.23 & 57.9 & 0.92 & 33.4 & 0.18 \\
2DC & Minimum & 23.5 & 0.00 & 23.6 & 0.00 & 27.9 & 0.00 \\
& Maximum & 68.4 & 2.35 & 81.3 & 2.95 & 107.5 & 9.05 \\
& M ean & 39.5 & 0.24 & 42.9 & 0.44 & 47.0 & 0.60 \\
3DC & Minimum & 19.2 & 0.00 & 25.2 & 0.00 & 27.8 & 0.00 \\
& Maximum & 90.0 & 2.97 & 102.7 & 5.25 & 129.9 & 6.35 \\
& Mean & 41.5 & 0.29 & 57.3 & 0.91 & 53.1 & 0.77 \\
\end{tabular}

cipitation maximum is located over the south-southwestern portion of the basin. Most of the precipitation in Storm 2 is associated with the warm front (shown before $40 \mathrm{~h}$ in Fig. 5a). This front moved north slowly and, as it reached the Upper West Branch of the SRB, its interaction with the topography of the region in MM5 (Fig. 7) resulted in the bands of precipitation, parallel to the ridges, shown in Fig. $6 a$ for the 2DC and 3DC.

The topography maps used by M M 5 are a result of the objective analysis of terrain-height data, followed by the use of a smoothing procedure to repassing directly over the southern limits of the SRB and dragging its stratiform cloud shield over the Upper West Branch of the SRB. As the primary surface low approached northwestern Pennsylvania, the rainfall from the secondary low blended with the rain ahead of the primary low's warm front and produced uninterrupted heavy rainfall. Ultimately, the primary low's cold front replaced its warm front and generated intense showers. Because this frontal band moved slowly over the basin as the secondary surface low stalled, the duration of this shower activity was extended. The system averaged approximately $4 \mathrm{~mm} \mathrm{~h}^{-1}$ of precipitation during the $>1.5 \mathrm{~d}$ period starting in the very early hours of $28 \mathrm{May}$, but had a maximum of $13 \mathrm{~mm} \mathrm{~h}^{-1}$ on 28 May 15:00 to 16:00 UTC.

The major difference in the temporal evolution of the areally averaged MM 5-simulated precipitation and the GIS-HM S-simulated direct surface runoff for Storm 2 (Fig. 5) is the precipitation peak in the 1DC at approximately $48 \mathrm{~h}$ into the simulation. Otherwise, the trends observed in Storm 1 for the 2DC and the 3DC are also present in Storm 2. Except for the second major peak in the surface runoff traces, the 3DC has the highest surface runoff hydrograph peaks and the 2DC has the lowest hydrograph peaks. The temporal evolution of the surface runoff response for all 3 cases is consistent with the temporal evolution of the simulated precipitation.

In the 3DC and 2DC, the spatial distribution of the temporally integrated precipitation (Fig. 6a) shows a primary band of maximum values located in the southwest-northeast direction, close to the southeastern boundary of the basin. The 3DC and 2DC precipitation also show a second band, parallel to the first one, but across the middle of the domain. This band is better defined in the 3DC than in the $2 \mathrm{DC}$. For the 1DC, the pre- move the shorter waves (Guo \& Chen 1993). The result of this procedure is a topography map with lower resolution than the grid increment of the domain for
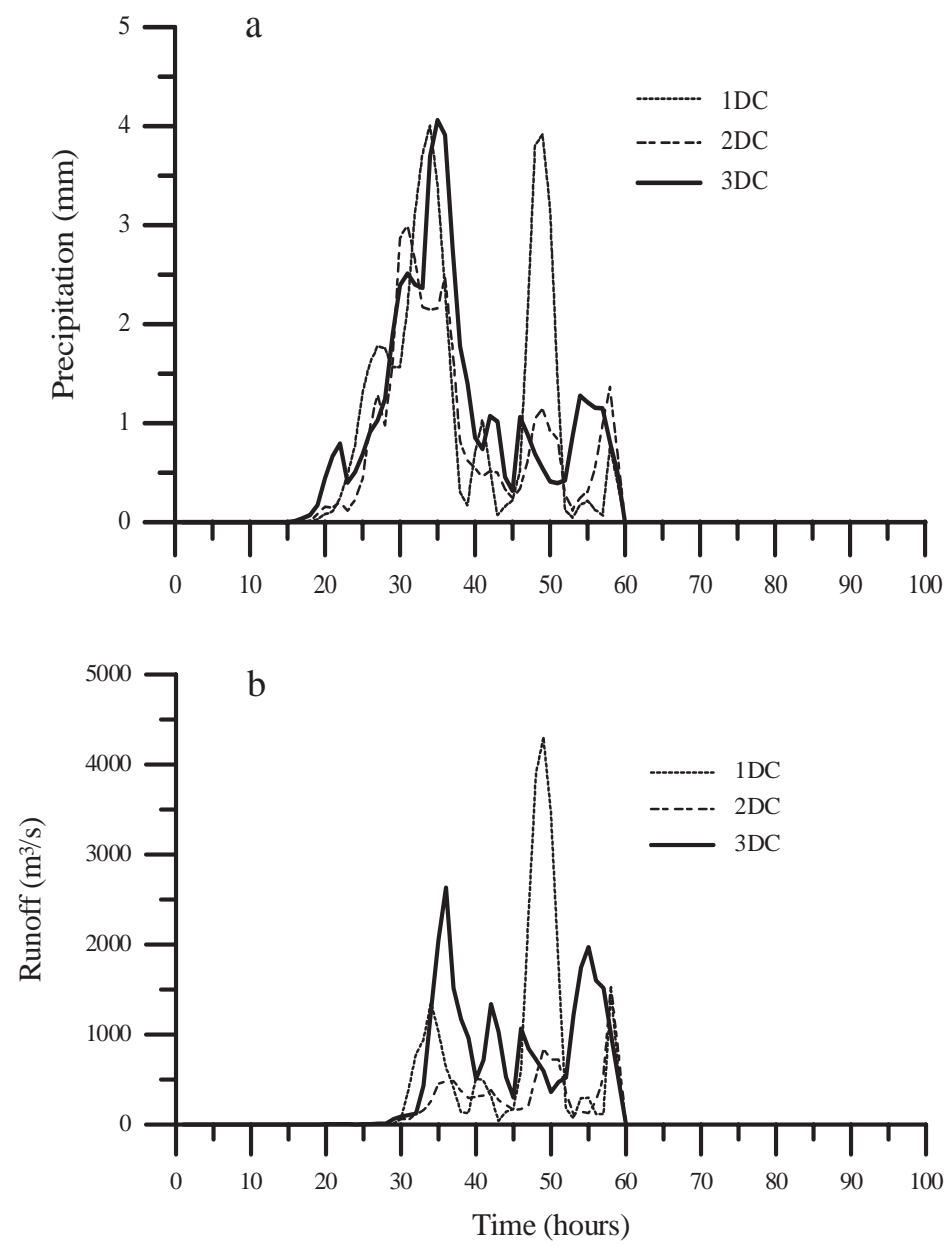

Fig. 5. Temporal evolution of the areally averaged (a) M M 5-simulated precipitation and (b) GIS-HMS-simulated direct surface runoff over the Upper West Branch of the SRB for the 1DC, 2DC and 3DC for Storm 2 (starting at 12:00 UTC 27 M ay 1984) 

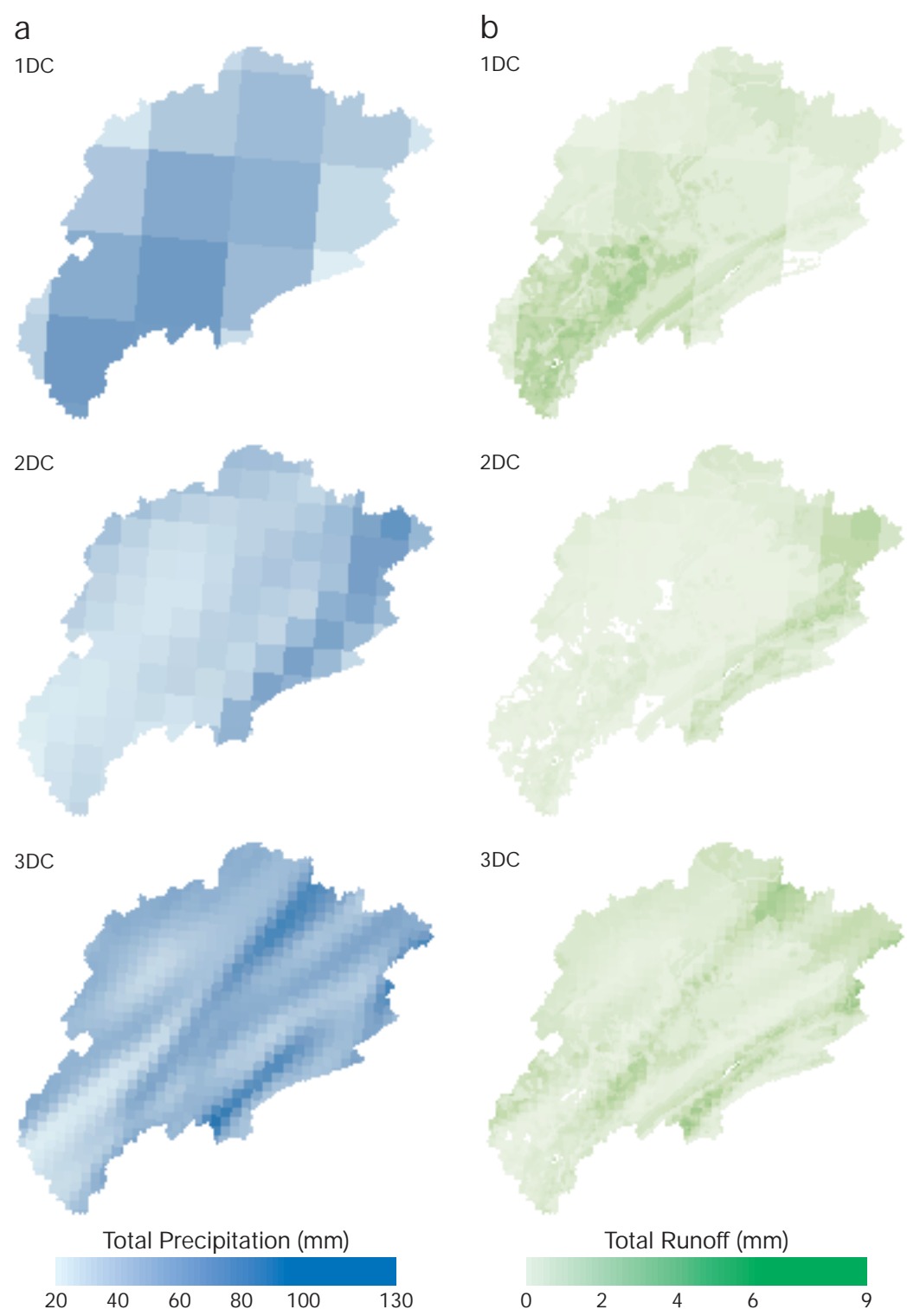

Fig. 6. Spatial distribution of the temporally integrated (a) M M 5-simulated precipitation and (b) GIS-HMS-simulated direct surface runoff over the Upper West Branch of the SRB for the 1DC, 2DC and 3DC for Storm 2 (starting at 12:00 UTC 27 M ay 1984)

which it is intended. Therefore, the $4 \mathrm{~km}$ topography map for the area in and around the Upper West Branch of the SRB (Fig. 7c) shows the major features of the A ppalachian Plateau and the Appalachian Mountains, compared to those shown in Fig. 2 ( $1 \mathrm{~km}$ resolution). The $12 \mathrm{~km}$ map (Fig. $7 \mathrm{~b}$ ) shows a smoothed version of the $4 \mathrm{~km}$ map. However, the $36 \mathrm{~km}$ topography map (Fig. 7a) shows a very different picture, with an approximately constant gradient in the southeastnorthwest direction.

The difference in the precipitation distribution results in different patterns of GIS-HMS-simulated surface runoff fields for the 1DC compared to the other 2 cases (Fig. 6b). The 3DC and 2DC show a band of maximum surface runoff that coincides with the primary band of precipitation. The 3DC also shows a band of maximum surface runoff associated with the second precipitation band, which is not noticeable in the 2DC. The maximum value of precipitation increases as the grid resolution increases (Table 2). The minimum and mean values of precipitation and maximum and mean values of surface runoff are similar for the IDC and 3DC.

\subsection{Storm 3: M ay 1988}

Unlike the classic mid-latitude wave cyclones described above, the May 1988 storm was an upper-level, cut-off low-pressure system with no discernible surface fronts. This longlived, stationary system settled over the SRB on $9 \mathrm{M}$ ay, generating measurable, but spatially and temporally discontinuous, rainfall every day until 25 May. On 18 May, one particularly strong convective pulse of the cut-off low produced heavy showers on the moist, perhaps saturated, soils of the Upper West Branch of the SRB and is modeled here.

Similar to Storm 1, the temporal evolutions of the areally averaged M M 5-simulated precipitation over the basin in Storm 3 are similar to each other for the 3 cases (Fig. 8a). In particular, the strong convective pulse observed on $18 \mathrm{M}$ ay is well defined in all 3 cases (in particular in the 2DC and 3DC) 25 to $36 \mathrm{~h}$ into the simulation (approximately between 13:00 UTC 18 May and 00:00 UTC 19 $M$ ay). The highest precipitation value increases as the grid resolution increases. The same trends as in precipitation are observed in the GIS-HMS-simulated direct surface runoff traces for all 3 cases (Fig. 8b). The surface runoff response to the 1DC precipitation is very small compared to the other 2 higher-resolution cases. This discrepancy indicates that for this type of storm system low-resolution MM 5-simulated precipitation is not a good choice to drive the basin hydrologic response. 
a
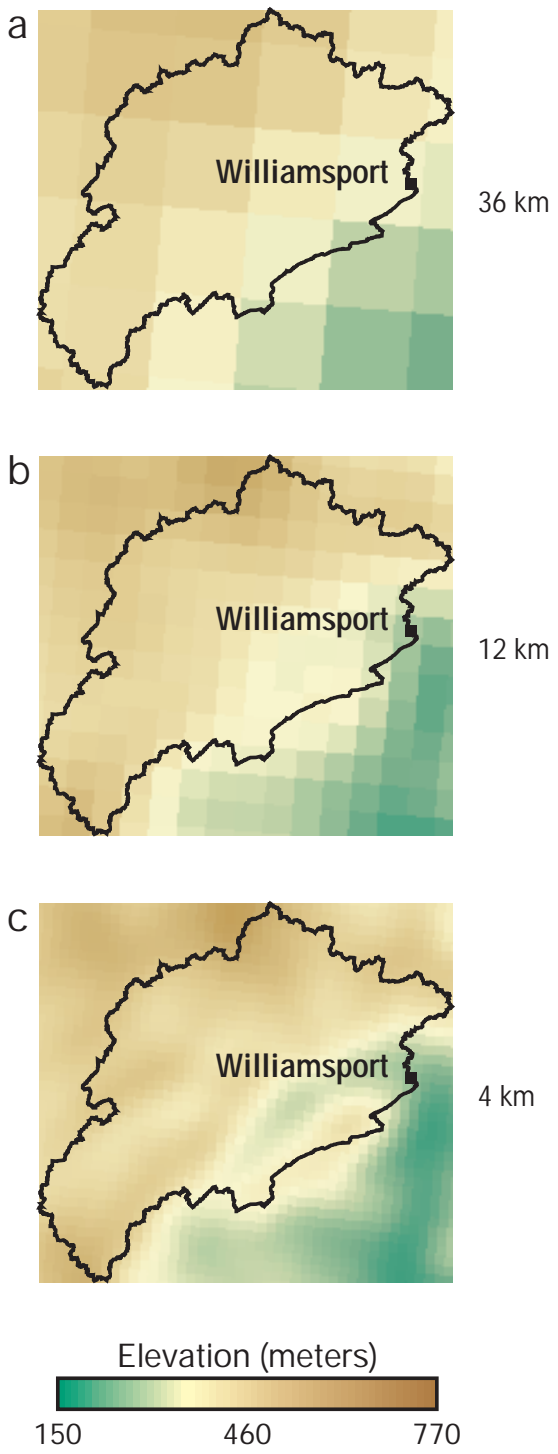

Fig. 7. The topography maps used by MM 5 over the Upper West Branch of the SRB and surrounding area for: (a) Domain 1 (1DC), (b) Domain 2 (2DC), and (c) Domain 3 (3DC)

The spatial distributions of the temporally integrated precipitation for Storm 3 are consistent among the 3 cases (Fig. 9a). The highest precipitation fields for all 3 cases are located in the southwestern corner of the basin, with the IDC precipitation field showing much lower values throughout the area. The spatial patterns of surface runoff (Fig. 9b) are also very similar for 2DC and 3DC. The maximum and mean values of precipitation and the mean value of surface runoff increase with the resolution, while the minimum value of precipitation is similar for all 3 cases (Table 2).

\section{DISC USSION}

The results show that the $2 \mathrm{DC}$ generates similar patterns of MM 5-simulated precipitation and GIS-HMSsimulated direct surface runoff to those of the 3DC. The IDC produces unrepresentative precipitation distributions in time and space. These results integrate the effect that the MM 5 resolution has on the simulated precipitation, and the effect that the resolution of the precipitation fields has on the GIS-HM S-simulated direct surface runoff.

In order to isolate the effect that the precipitation resolution has on the GIS-HMS-simulated direct surface runoff, the MM5-simulated $4 \mathrm{~km}$ precipitation fields (3DC) for Storm 3 were transformed into 12 and $36 \mathrm{~km}$ precipitation fields. This was done by averaging the precipitation values for the 9 (81) $4 \mathrm{~km}$ grid points around each 12 (36) km grid point. Then the GIS HMS was driven by these 3 precipitation data sets. Fig. 10 shows the temporal evolution of the areally averaged
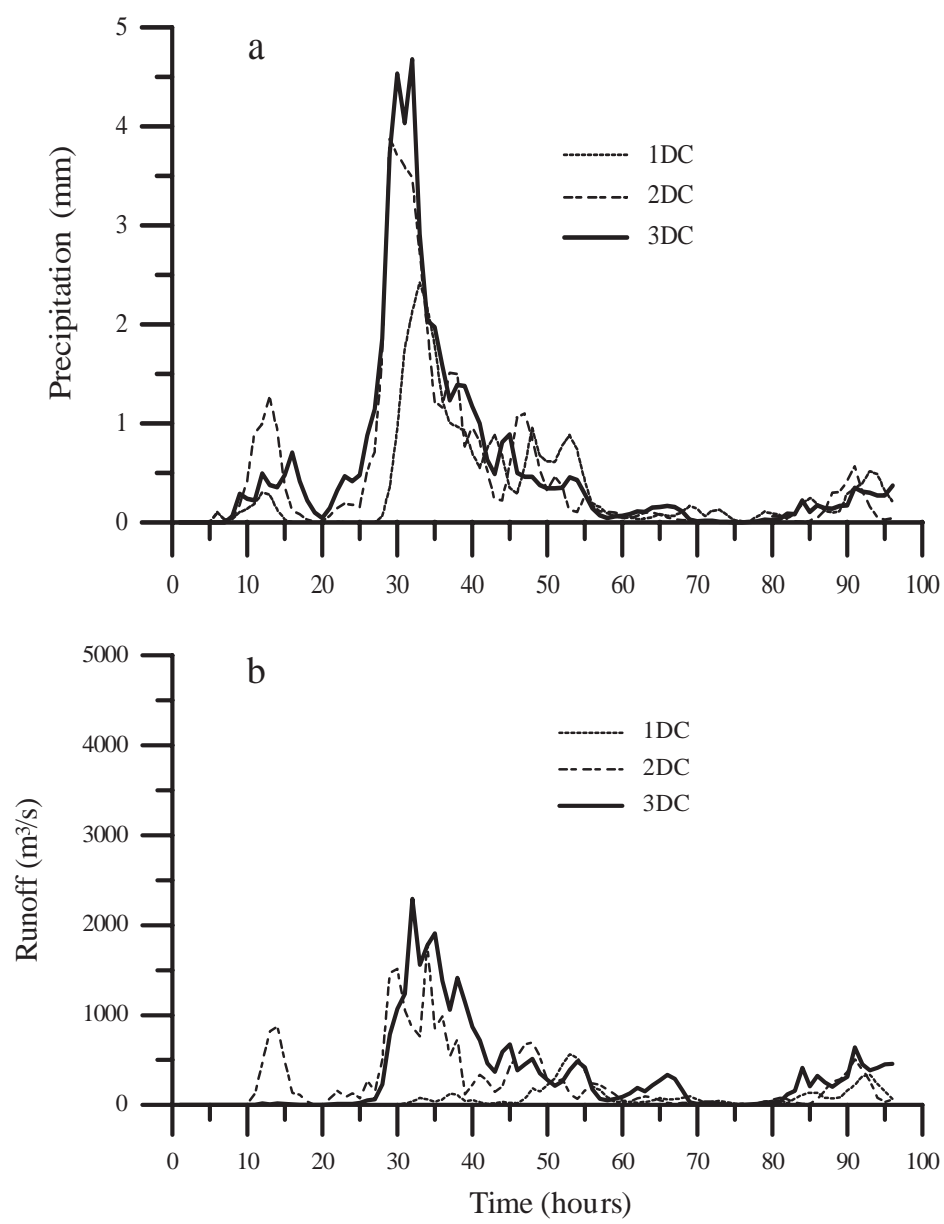

Fig. 8. Temporal evolution of the areally averaged (a) M M 5-simulated precipitation and (b) GIS-HMS-simulated direct surface runoff over the Upper West Branch of the SRB for the 1DC, 2DC and 3DC for Storm 3 (starting at 12:00 UTC 17 M ay 1988) 


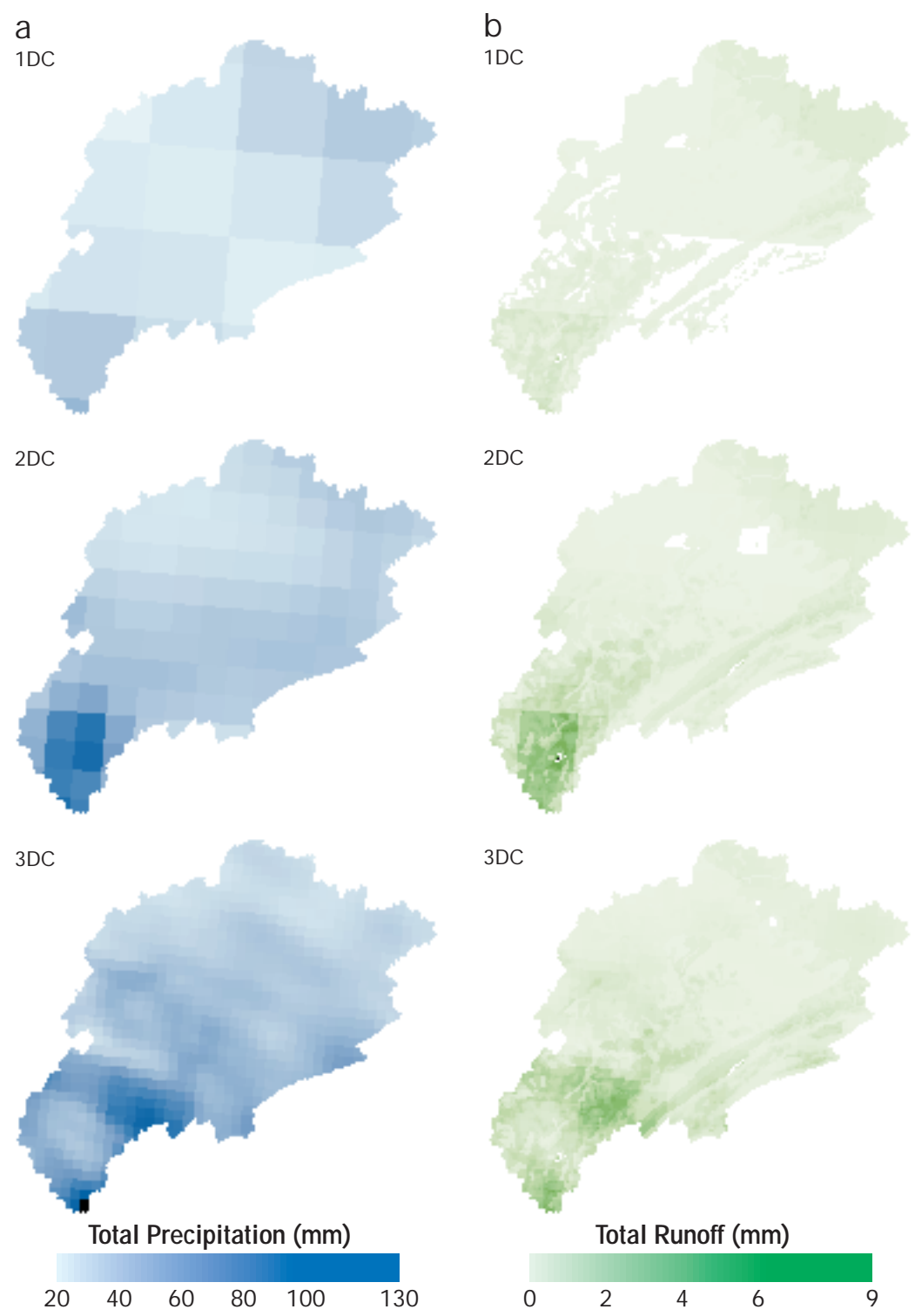

Fig. 9. Spatial distribution of the temporally integrated (a) M M 5-simulated precipitation and (b) GIS-HMS-simulated direct surface runoff over the Upper West Branch of the SRB for the 1DC, 2DC and 3DC for Storm 3 (starting at 12:00 UTC 17 May 1988)

precipitation and the GIS-HMS-simulated direct surface runoff over the Upper West Branch of the SRB for Storm 3, in the form of differences between the transformed cases and the 3DC. The small differences in the precipitation traces (Fig. 10a) arise from the fact that the upscaling from $4 \mathrm{~km}$ to 12 and $36 \mathrm{~km}$ was done over the square grid cells of the entire MM5 $4 \mathrm{~km}$ domain, whereas the precipitation shown in Fig. 10a is only for the part of the M M 5 domain which falls within the boundaries of the Upper West Branch of the SRB (i.e. the GIS HMS domain). Thus for some 12 and $36 \mathrm{~km}$ grid cells which straddle the basin boundaries, the average precipitation for the $4 \mathrm{~km}$ cells outside the boundary may be different from that for the $4 \mathrm{~km}$ cells inside the boundary. The $4 \mathrm{~km}$ cells outside the boundary do contribute, however, to the 12 and $36 \mathrm{~km}$ average precipitation. The differences in the direct surface runoff are very small compared to the differences among the 1DC, 2DC and 3DC GIS-HMS-simulated runoff traces (Fig. 8). The spatial distributions of the temporally integrated precipitation and GIS-HMSsimulated direct surface runoff for the 3DC and for the transformed 12 and $36 \mathrm{~km}$ cases (not shown) also display very small differences among the 3 cases. Therefore, in order to evaluate the effect that the MM 5 resolution has on the GIS HMS simulation of direct surface runoff in these linked-model experiments, the primary focus must be on the effect that the MM 5 resolution has on the simulated precipitation.

There are many reasons why the simulations with the 1DC, 2DC and 3DC result in different precipitation outputs. The most obvious one is that higher resolution in the M M 5 horizontal domain (i.e. a smaller grid increment) may lead to a better simulation. This is based on the realistic expectation that, with higher resolution, M M 5 resolves smaller-scale features that may become sub-grid-scale features, or may not even be present, with lower resolution. With higher resolution the MM 5 internal dynamics may develop small-scale features that may play key roles in simulating the hydrologic processes realistically. Also, as the MM 5 resolution increases, the topographic features are better represented (Fig. 7), the horizontal distribution of the surface characteristics (e.g. albedo and surface roughness) are much more realistic, and more small-scale precipitation processes are resolved, as opposed to being parameterized. These are all important features because the spatial variability in the direct surface runoff is controlled by the small-scale patterns of precipitation, along with the spatial distribution of soil characteristics and vegetation cover.

A good example of the effect of topographic features on the MM5 results is given by Storm 2 (Fig. 6a), where, for the $2 D C$ and $3 D C$, the interaction between 

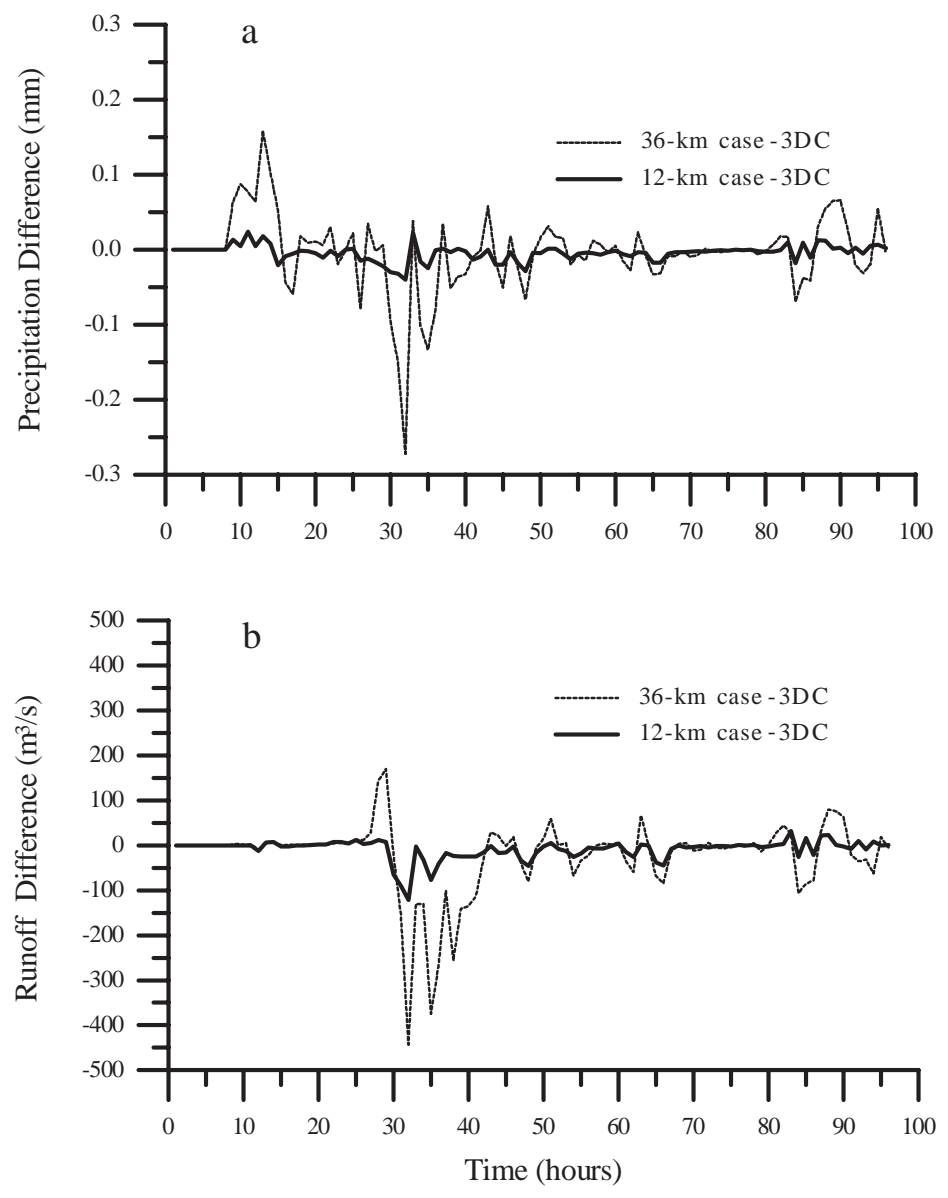

Fig. 10. Temporal evolution of the areally averaged (a) M M 5-simulated precipitation and (b) GIS-HMS-simulated direct surface runoff over the Upper West Branch of the SRB, shown as differences between the transformed cases and the 3DC for Storm 3 (starting at 12:00 UTC 17 May 1988)

the warm-front circulation and the local topography (Fig. $7 \mathrm{~b}, \mathrm{c})$ materialized in the bands of precipitation parallel to the ridges. However, this interaction is not apparent in the 1DC, where the low resolution of the topography (Fig. 7a) did not resolve the valleys and ridges.

When small-scale precipitation processes are not resolved, they are parameterized using cumulus parameterization schemes. As explained in a previous section, the cumulus parameterization scheme was used only for Domains 1 and 2. Therefore, while some of the precipitation processes were parameterized in Domains 1 and 2, all the precipitation produced in Domain 3 resulted from grid-resolved processes. This may explain some of the differences in the precipitation amounts in all 3 storms.

A nother reason why the simulations with the 1DC, 2DC and 3DC resulted in different precipitation outputs may be the way the initial conditions were defined. As explained in a previous section, the initial conditions for Domains 1 and 2 were obtained using an objective analysis procedure based on the observations. On the other hand, the initial conditions for Domain 3 were created by interpolating the analyses from Domain 2 to the $4 \mathrm{~km}$ grid at the MM5 initial time. Shortterm simulations like the ones for Storms 1 to 3 are influenced by the initial conditions much more than longer-term ones. Therefore, this difference may partly explain why the results of the $2 D C$ and $3 D C$ are closer than those of the IDC and 3DC for all 3 storms.

Although using MM 5 with higher resolution may lead to a better precipitation simulation, there are some factors that may counteract this effect, to the point of rendering the higherresolution effort useless or unattainable. The final goal of the SRBEX IDS group is to understand the regional impacts of climate change. Therefore, the long-range plans include the simulation, with a hierarchy of linked models, of the SRB's response to single-storm events, a sequence of storms, the annual cycle, El NiñoSouthern Oscillation forcing, and increased atmospheric greenhouse-gas concentrations. The first step (i.e. the simulation of single-storm events) has already been taken successfully (Lakhtakia et al. 1998, Yu et al. 1999a). The immediate next steps are to simulate a sequence of storms and the annual cycle. For these longer-term applications, MM 5 will be modified to act as a RegCM. In that case, the initial conditions and the lateral boundary conditions for the MM5-based RegCM will be given by a GCM. The longer the RegCM simulation is, the more important the lateral boundary conditions become. This may be a source of multiple 'errors' for the RegCM simulation, as discussed in detail by Warner et al. (1997). They pointed out that, when the lateral boundary conditions are given by a GCM , some of the factors that may contribute to errors within a limited-area model like MM 5 are: (1) the difference in the resolution between the GCM and M M 5 grids, resulting in the need for interpolating the information at the MM 5-domain lateral boundaries; (2) the fact that the GCM is a numerical model and, as such, its simulations may be less than perfect; (3) the differences in the physical-process parameterizations between the GCM and MM5; and (4) the 1-way nesting between the 2 models.

In order to minimize the difference in resolution between the GCM and RegCM grids, the latter model will be set up with a lower-resolution domain, with a grid increment of $108 \mathrm{~km}$, within which the 36 , the 12 
and perhaps the $4 \mathrm{~km}$ domains will be nested. Although the RegCM will be modified as much as possible to reduce the differences between its physicalprocess parameterizations and those of the GCM, a perfect match is not feasible. Finally, the link between the GCM and the RegCM will be through a 1-way nesting. As such, there will be no feedback from the RegCM to the GCM. In summary, the MM5-based RegCM will be modified to reduce some of the potential errors. Unfortunately, it is virtually impossible to eliminate those errors al together.

For the simulations presented here, MM 5 was executed on a CRAY-J 90 supercomputer with 16 processors; all 9 simulations used multi-processing. Based on the statistics from these simulations, rough estimates of the time it takes to perform a simulation for each of the cases using a single processor are $0.08,0.62$ and 2.01 wall-clock hours per hour of simulation for the 1DC, $2 \mathrm{DC}$ and $3 \mathrm{DC}$, respectively. Therefore, to make a $1 \mathrm{yr}$ simulation with the MM 5-based RegCM set up in the same way as for the applications presented here, using 4 processors, and including the $108 \mathrm{~km}$ domain (which would add less than 1 wall-clock day for a $1 \mathrm{yr}$ simulation) it would take approximately $8.3 \mathrm{~d}$ for $108-36 \mathrm{~km}$ case, $57.4 \mathrm{~d}$ for $108-36-12 \mathrm{~km}$ case, and $184.7 \mathrm{~d}$ for the 108-36-12-4 km case.

\section{CONCLUSIONS}

The need to produce high-resolution regional climate scenarios led the SRBEX IDS group to test the sensitivity of the GIS-HMS-simulated direct surface runoff to the MM 5 resolution. The issue at hand is to provide empirical guidelines for how fine the MM5 grid increment must be for hydrology and waterresource-management applications.

The sensitivity tests simulated 3 single-storm events over the SRB using M M 5 with 3 nested-domain set-ups (1DC, 2DC and 3DC). The MM 5-simulated precipitation fields were used as the link to a rainfall-runoff version of the GIS HMS that simulated the direct surface runoff over the Upper West Branch of the SRB. The spatial and temporal distribution of the resulting IDC and 2DC precipitation and direct surface runoff were compared to those of the 3DC (i.e. the control runs).

The results show that, compared to the $3 D C$, the 2DC generates more realistic precipitation distributions in space and time than the 1DC. These spatial differences in the precipitation distributions result in different spatial hydrologic responses. The performance of the simulated hydrologic response improves as the simulated-precipitation resolution increases. However, keeping in mind the near-future regionalclimate-change applications of these linked models, i.e. given the extraordinary computing demands of a 3DC simulation and the potential sources of error that may come into play in a simulation that links the GCM, M M 5-based RegCM, and HMS, the 2DC appears to be a suitable compromise. The $12 \mathrm{~km}$ grid increment of the $2 \mathrm{DC}$ provides a reasonable simulation of the precipitation fields and, ultimately, an acceptable surface runoff response.

Acknowledgements. This work was funded by the NASA EOS interdisciplinary research project 'The Global Water Cycle: Extension Across the Earth Sciences', Eric J. Barron, Principal Investigator (NAGW-2686 and NAG5-4553). Special thanks goes to Eric J. Barron for his advice and encouragement. J on Voortman is gratefully acknowledged for running the GIS HMS simulations, and Phil Kolb is thanked for his skillful preparation of the figures. The manuscript was much improved as a result of the suggestions of the 2 reviewers. Their contributions are greatly appreciated. All computations were performed at the 'Earth System Science Center' computer facility, which includes a SUN workstation network and a CRAY J-series computer, and whose staff is acknowledged with thanks for their continued support. The source of the data used for initializing MM5 is the National Center for Atmospheric Research, which is operated by the University Corporation for Atmospheric Research and sponsored by the National Science Foundation.

\section{LITERATURE CITED}

Bedient PB, Huber WC (1992) Hydrology and floodplain analysis. Wesley Publishing Company, Reading, MA

Beniston M, Pielke RA Sr, Arpe K, Keuler K, Laprise R, Mann ME, Rinke A, Parker DE (1997) Climate modelers meet in Switzerland. EOS 78:484

Crane RG, Hewitson BC (1998) Doubled $\mathrm{CO}_{2}$ precipitation changes for the Susquehanna basin: down-scaling from the GENESIS general circulation model. Int J Climatol 18: 65-76

Crane RG, Yarnal B, Barron EJ, Hewitson BC (1999) Scale interactions and regional climate: examples from the Susquehanna River Basin. Human Ecol Risk Assess (in press)

Dudhia J (1993) A nonhydrostatic version of the Penn StateNCAR mesoscale model: validation tests and simulation of an Atlantic cyclone and cold front. M on Weather Rev 121: 1493-1513

Giorgi F, Mearns LO (1991) Approaches to simulation of regional climate change: a review. Rev Geophys 29: 191-216

Giorgi F, Marinucci M R, Bates GT (1993a) Development of a second-generation regional climate model (RegCM 2). Part I: Boundary-layer and radiative transfer processes. Mon Weather Rev 121:2794-2813

Giorgi F, Marinucci MR, Bates GT (1993b) Development of a second-generation regional climate model (RegCM2). Part II: Convective processes and assimilation of lateral boundary conditions. M on Weather Rev 121:2814-2832

Grell GA (1993) Prognostic evaluation of assumptions used by cumulus parameterizations. Mon Weather Rev 121: 764-787

Grell GA, Dudhia J, Stauffer DR (1995) A description of the fifth-generation Penn State/NCAR Mesoscale Model (MM 5). NCAR/TN-398+STR, National Center for Atmo- 
spheric Research, Boulder, CO

Guo YR, Chen S (1993) Terrain and land use for the fifth-generation Penn State/NCAR mesoscale modeling system (MM 5): program TERRAIN. NCAR/TN-397+HA, National Center for Atmospheric Research, Boulder, CO

Hewitson BC, Crane RG (1996) Climate downscaling: techniques and application. Clim Res 7:85-95

J enkins G, Barron EJ (1997) General circulation model and coupled regional climate model simulations over the eastern United States: GENESIS and RegCM 2 simulations. Global Planet Change 15:3-32

Kattenberg A, Giorgi F, Grassl H, Meehl GA, Mitchell J FB, Stouffer RJ, Tokioka T, Weaver AJ, Wigley TML (1996) Climate models - projections of future climate. In: Houghton JT, Meira Filho LG, Callander BA, Harris N, Kattenberg A, Maskell K (eds) Climate change 1995: the science of climate change. Cambridge University Press, Cambridge, p 285-357

Lakhtakia MN, Yarnal B, J ohnson DL, White RA, Miller DA, Yu Z (1998) A simulation of river-basin response to mesoscale meteorological forcing: the Susquehanna River Basin experiment (SRBEX). J Am Water Resour Assoc 34: 921-937

Manning KW, Haagenson PL (1992) Data ingest and objective analysis for the PSU/NCAR modeling system: programs DATAGRID and RAWINS. NCAR/TN-376+HA, National Center for Atmospheric Research, Boulder, CO

Marsh B, Lewis P (1995) Landforms and human habitat. In: Miller EW (ed) A geography of Pennsylvania. The Pennsylvania State University Press, University Park, PA, p 17-43

Miller DA, White RA (1998) A conterminous United States

Editorial responsibility: Hans von Storch, Geesthacht, Germany multi-layer soil characteristics data set for regional climate and hydrology modeling. Earth Interact 2-002. Available online at http://EarthInteractions.org

NOAA (1984, 1986, 1988) Daily weather maps, weekly series. National Oceanic and Atmospheric Administration, Washington, $\mathrm{DC}$

Thompson SL, Pollard D (1995) A global climate model (GENESIS) with a land-surface-transfer scheme (LSX). Part 1: Present climate simulations. J Clim 8:732-761

USDA-SCS (1972) National engineering handbook. Section 4-Hydrology. United States Department of Agriculture, Soil Conservation Survey, Washington, DC

USEPA (1994) EMAP Chesapeake Bay watershed pilot project final report. US Environmental Protection Agency, Office of Research and Development, Environmental M onitoring Systems Laboratory, Las Vegas, NV

Warner TT, Peterson RA, Treadon RE (1997) A tutorial on lateral boundary conditions as a basic and potentially serious limitation to regional numerical weather prediction. Bull Am Meteorol Soc 78:2599-2617

Yu Z, Lakhtakia MN, Yarnal B, White RA, Miller DA, Frakes B, Barron EJ, Duffy C, Schwartz FW (1999a) Simulating the river-basin response to atmospheric forcing by linking a mesoscale meteorological model and a hydrologic model system. J Hydrol 218:72-91

Yu Z, Guo Y, Voortman J , White RA, Miller DA (1999b) Storm simulation using a geographical information system with a distributed approach. Transact GIS (in press)

Zhang DL, Anthes RA (1982) A high-resolution model of the planetary boundary layer - sensitivity tests and comparisons with SESAME-79 data. J Appl Meteorol 21: 1594-1609

Submitted: J uly 2, 1998; Accepted: February 17, 1999 Proofs received from author(s): May 31, 1999 